\title{
Three-level (NPC) Shunt Active Power Filter Performances based on Fuzzy Controller for Harmonic Currents Compensation under Non-Ideal Voltage Conditions
}

\author{
Chennai Salim ${ }^{1}$ and Benchouia Mohamed Toufik ${ }^{2}$ \\ ${ }^{1}$ Electrical Engineering Department, Birine Nuclear Research Center, Algeria, \\ ${ }^{2}$ Laboratory L.G.E.B., Biskra University, Algeria \\ chenaisalimov@yahoo.fr
}

\begin{abstract}
This paper presents three-level (NPC) shunt active power filter the performances based on fuzzy control techniques to compensate harmonic currents generated by non-linear loads operating under non ideal voltage conditions. Shunt APF is the best solution to eliminate harmonics drawn from nonlinear load especially for low power system, the most inverter used is the two-level voltage source inverter. Multilevel inverters are being investigated and recently used for APF topologies. Today Threelevel inverter is one of the most used converters in the majority of industrial applications, such as machine drives and power active filters. The control strategy used is based on the synchronous reference frame detection method that gives a good performance particularly if the source voltage is unbalanced or distorted. The new control scheme proposed in this work is based on fuzzy techniques and it is designed to improve APF compensation capability by adjusting the current error based on fuzzy rule. To improve the output three-level voltage inverter and avoid an unbalanced AC voltage waveform a neutral-point potential voltage compensator based on proportional controller is used with a proportional integral controller required to maintain de voltage constant. The results of simulation study obtained using Matlab-Simulink and SimPowerSystem Toolbox are found quite satisfactory to eliminate harmonics and reactive power components from utility current.
\end{abstract}

Keywords: Shunt active filter, Three-level (NPC) inverter, Fuzzy logic current controller, Neutral point unbalances control, Harmonics compensation, Non-ideal voltage conditions.

\section{Introduction}

A large part of total electrical energy, produced in the world, supplies different types of non-linear loads. The loads such as variable frequency drives and electronic ballasts draw current, which does not resemble the grid sinusoidal voltage. This load is said to be non-linear and typically is composed of odd order currents, which are expressed as multiples of the fundamental frequency. The harmonic current cannot contribute to active power and need to be eliminated to enhance the power quality [1]. Active Power Filter (APF) is the popular solution used to eliminate the undesired current components by injection of compensation currents in opposition to them [2],[3]. The most power converter used in APF is the two-level voltage source inverter [4],[5], these inverter are limited for low power applications. The three-level neutral-point diode-clamped (NPC) active power filter has been playing an important role for medium and high power applications [6]. It provides less voltage stress for semiconductor switches, increases the power handling capability, reduces current/voltage harmonics and interference.

The controller is the main part of the active power filter operation and has been a subject of many researches in recent years [7],[8]; Among the various current control techniques, hysteresis current control is the most extensively used technique. It is easy to realize with high accuracy and fast response. In the hysteresis control technique the error function is centred in a

Received: April $4^{\text {th }}, 2013$. Accepted: May $14^{\text {th }}, 2014$ 
preset hysteresis band. When the error exceeds the upper or lower hysteresis limit the hysteretic controller makes an appropriate switching decision to control the error within the preset band. However, variable switching frequency and high ripple content are the main disadvantages of hysteresis current control. To improve the APF performances there's a great tendency to use intelligent control techniques, particularly fuzzy logic controllers. In recent years, fuzzy logic controllers have generated a great deal of interest in power electronics applications. These advantages are: robustness, no need accurate mathematical model, etc...

In this paper, fuzzy logic current controller is proposed to control three-phase shunt active filter based on three-level neutral point clamped (NPC) inverter. The fuzzy current controller is designed to improve compensation capability of APF by adjusting the current error using a fuzzy rule. The inverter current reference signals required to compensate harmonic currents use the synchronous reference detection method that gives good performance under non ideal voltage conditions. The performances of global system including control circuit and power structure are performed and evaluated through computer simulations for steady-state conditions using Matlab-simulink program and SimPowerSystem Toolbox.

\section{Shunt active power filter}

The circuit configuration of the three-level shunt active filter is shown in Figure 1. It is controlled to cancel current harmonics on AC side and makes the source current in phase with the voltage source. The current drawn from the power system at the coupling point of the shunt APF will result sinusoidal [9],[10] and [11].

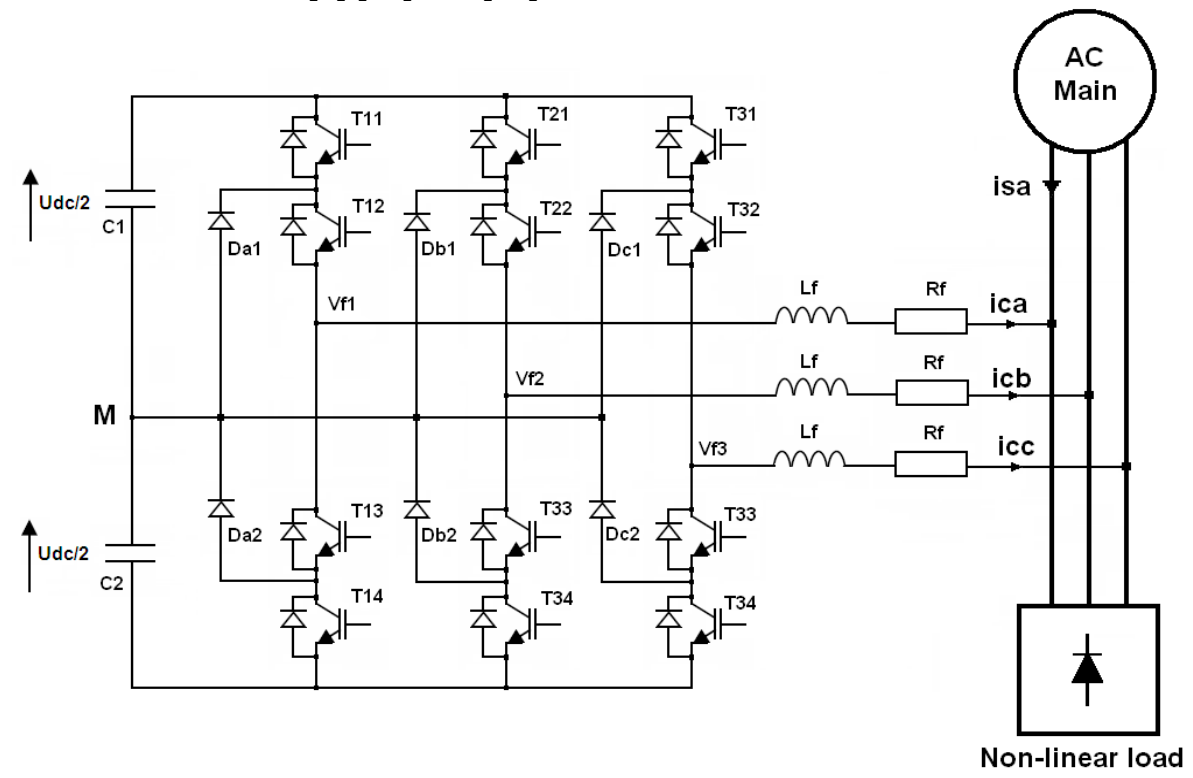

Figure 1. Three-level (NPC) Shunt active filter

Three-level inverter is one of the most popular converters employed in medium and high power applications. Their advantages include the capability to reduce the harmonic content and decrease the voltage or current ratings of the semiconductors [12],[13]. The power circuit of the three-level neutral point clamped inverter is based on six main switches (T11, T21, T31, T14, T24, T34) of the traditional two-level inverter, with six auxiliary switches (T12, T13, T22, T23, T32, T33) and two neutral clamped diodes added on each bridge arm. The diodes are used to create the connection with the point of reference to obtain midpoint voltages. This structure allows the switches to endure larger dc voltage input on the premise that the switches will not raise the level of their withstand voltage. For this structure, three output voltage levels can be obtained, namely, $\mathrm{Udc} / 2,0$, and $-\mathrm{Udc} / 2$ corresponding to three switching states $\mathrm{A}, 0$, 
and B. As a result, 27 states of switching output exist in the three-phase three-level (NPC) inverter.

\section{Control strategies}

The control strategy adopted in this work is the synchronous reference frame detection method. The principle of this technique is described below [14],[15]. The three phase load currents $i \mathrm{La}, \mathrm{iLb}$ and iLc are transformed from three phase (abc) reference frame to two phase's $(\alpha-\beta)$ stationary reference frame currents $i \alpha$ and i $\beta$ using:

$$
\left[\begin{array}{l}
\boldsymbol{i}_{\alpha} \\
\boldsymbol{i}_{\beta}
\end{array}\right]=\sqrt{2 / 3}\left[\begin{array}{ccc}
1 & -\frac{1}{2} & \frac{1}{2} \\
0 & \frac{\sqrt{3}}{2} & -\frac{\sqrt{3}}{2}
\end{array}\right]\left[\begin{array}{l}
\boldsymbol{i}_{\boldsymbol{L a}} \\
\boldsymbol{i}_{\boldsymbol{L b}} \\
\boldsymbol{i}_{\boldsymbol{L} \boldsymbol{c}}
\end{array}\right]
$$

Using a PLL (Phase Locked Loop), we can generate $\cos (\theta$ est) and $\sin (\theta$ est) from the phase voltage source vsa, vsb, vsc. The currents expression $i \alpha$ and i $\beta$ in $(d-q)$ reference frame are given by:

$$
\left[\begin{array}{l}
\dot{i}_{\boldsymbol{d}} \\
\dot{\boldsymbol{i}}_{\boldsymbol{q}}
\end{array}\right]=\left[\begin{array}{cc}
\sin \left(\theta_{\text {est }}\right) & -\cos \left(\theta_{\text {est }}\right) \\
\cos \left(\theta_{\text {est }}\right) & \sin \left(\theta_{\text {est }}\right)
\end{array}\right]\left[\begin{array}{c}
\boldsymbol{i}_{\alpha} \\
\boldsymbol{i}_{\beta}
\end{array}\right]
$$

The DC quantities and all other harmonics are transformed to non DC quantities using a low pass filter:

$$
\left[\begin{array}{c}
i_{d} \\
i_{q}
\end{array}\right]=\left[\begin{array}{c}
\overline{i_{d}}+\tilde{i}_{d} \\
i_{q}
\end{array}\right]
$$

The expression of the reference current i $\alpha$-ref and i $\beta$-ref are given by:

$$
\begin{aligned}
& {\left[\begin{array}{l}
i_{\alpha-r e f} \\
i_{\beta-r e f}
\end{array}\right]=\left[\begin{array}{cc}
\sin \left(\theta_{\text {est }}\right) & -\cos \left(\theta_{\text {est }}\right) \\
\cos \left(\theta_{\text {est }}\right) & \sin \left(\theta_{\text {est }}\right)
\end{array}\right]^{-1}\left[\begin{array}{c}
i_{d} \\
i_{q}
\end{array}\right]} \\
& {\left[\begin{array}{l}
i_{\alpha-r e f} \\
i_{\beta-r e f}
\end{array}\right]=\left[\begin{array}{cc}
\sin \left(\theta_{\text {est }}\right) & \cos \left(\theta_{\text {est }}\right) \\
-\cos \left(\theta_{\text {est }}\right) & \sin \left(\theta_{\text {est }}\right)
\end{array}\right]\left[\begin{array}{c}
\overline{i_{d}}+\tilde{i_{d}} \\
i_{q}
\end{array}\right]}
\end{aligned}
$$

Finally, the reference currents in the $(\mathrm{abc})$ frame are given by:

$$
\left[\begin{array}{l}
\boldsymbol{i}_{\boldsymbol{a}-\mathrm{ref}} \\
\boldsymbol{i}_{\boldsymbol{b}-\mathrm{ref}} \\
\boldsymbol{i}_{\boldsymbol{c}-\mathrm{ref}}
\end{array}\right]=\sqrt{2 / 3}\left[\begin{array}{cc}
1 & 0 \\
-\frac{1}{2} & \frac{\sqrt{3}}{2} \\
\frac{1}{2} & -\frac{\sqrt{3}}{2}
\end{array}\right]\left[\begin{array}{l}
\boldsymbol{i}_{\alpha-\mathrm{ref}} \\
\boldsymbol{i}_{\beta-\mathrm{ref}}
\end{array}\right]
$$

The principle scheme of synchronous reference frame control strategy for shunt active filter based on the three-level (NPC) inverter is shown in Figure 2. 


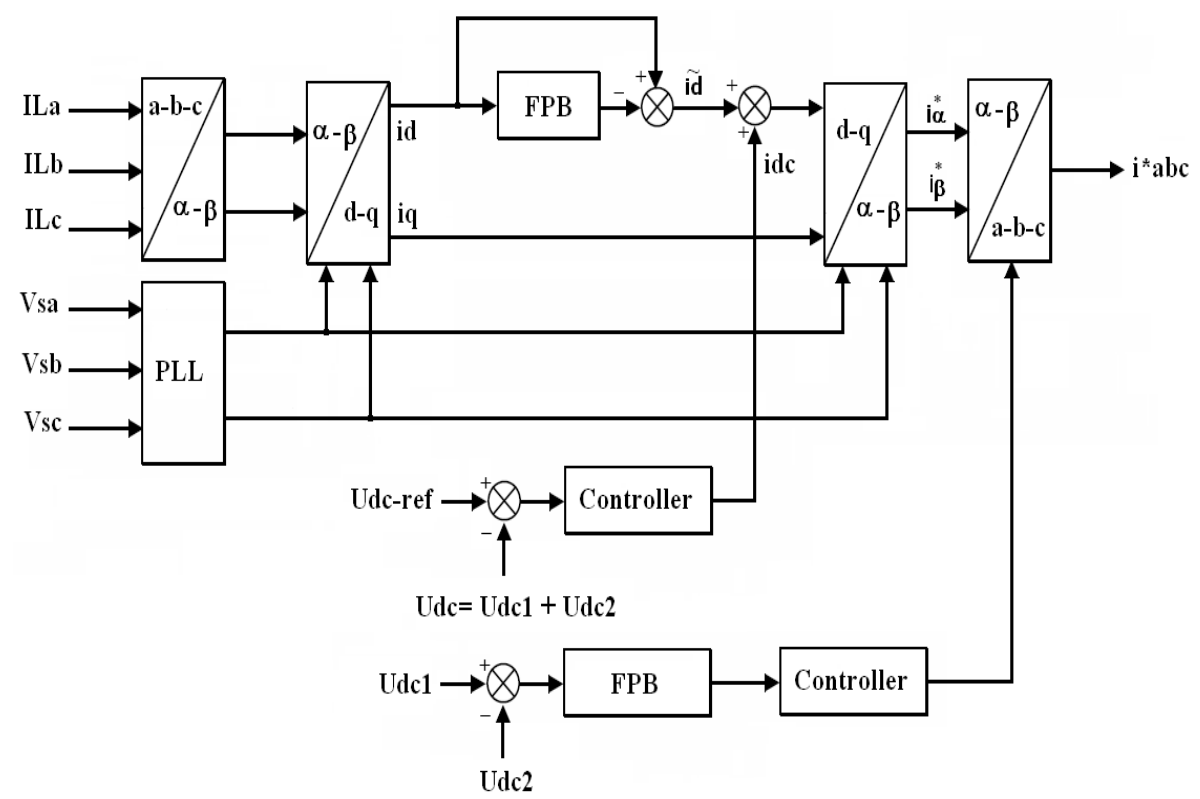

Figure 2. Synchronous reference frame control strategies

\section{Neutral point unbalances control}

To compensate the inverter losses and regulate the DC link voltage Udc, a proportional integral voltage controller is used in outer loop to determine the line current Ic,los. The control loop consists of the comparison of the measured voltage (Udc1 + Udc2) with the reference voltage Udc-ref [16],|[17]:

$$
I_{c, l o s}=K_{p} \cdot \Delta U_{d c}+K_{i} \int \Delta U_{d c} \cdot d t
$$

Neutral-point potential unbalance is a problem of NPC multilevel inverter, the compensation is required to avoid an unbalanced $\mathrm{AC}$ voltage waveform on the $\mathrm{AC}$ terminals. To compensate the neutral-point voltage a proportional controller is adopted in the inner control loop. If the average voltage across capacitor $\mathrm{C} 1$ is greater than the average voltage across capacitor $\mathrm{C} 2$, a small negative DC term current is added to the line current so that in the next source period the charged voltage in capacitor $\mathrm{C} 1$ is less than the charged voltage in capacitor C2. If the average voltage Udc1 is less than Udc2, a small positive DC current can be added to the line current in order to increase the capacitor voltage Udc1 in the next source period. Therefore, the additional compensated current for the neutral-point voltage balance is given as:

$$
i_{n p c}=L P F\left(U_{d c 2}-U_{d c 1}\right) \cdot K
$$

$\mathrm{K}$ is a small gain of the neutral-point voltage compensator. Figure 3 shows a control scheme of the neutral point potential compensator.

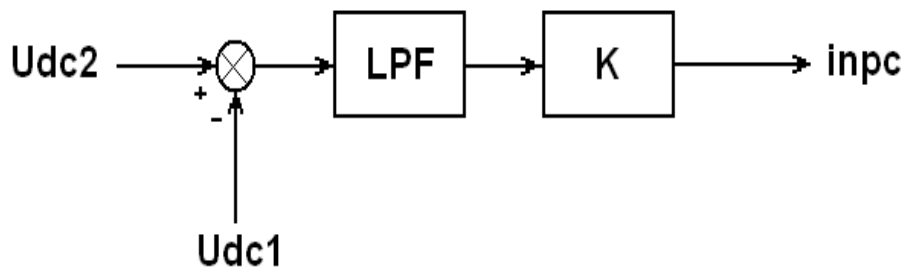

Figure 3. Neutral point potential compensator 


\section{Fuzzy logic control}

The main component of an active filter is the current controller. Recently, fuzzy logic controllers (FLCs) have been interest a good alternative in more application. The advantages of fuzzy controllers are more robust than conventional controllers, not need a mathematical model and can handle non-linearity [18],[19], and [20]. Fuzzy logic control is the evaluation of a set of simple linguistic rules to determine the control action. The desired inverter switching signals of the shunt active filter are determined according the error between the compensate currents and reference currents. A fuzzy controller is designed to improve compensation capability of APF by adjusting the current error using a fuzzy rule. In this case, the fuzzy logic current controller has two inputs, named error e and change of error de and one output s. To convert it into linguistic variable, we use three fuzzy sets: N (Negative), ZE (Zero) and P (Positive). Membership functions used for the inputs and the single output are shown is shown in Figure 4.

The parameter for the fuzzy logic current controller for every phase is characterized for the following:

The fuzzy controller for every phase is characterized for the following:

- Three fuzzy sets "e" and "de" inputs,

- Five fuzzy sets for "s" output,

- Gaussian membership functions for inputs,

- Triangular and trapezoidal membership functions for output,

- Implication using the "min" operator,

- Mamdani fuzzy inference mechanism based on fuzzy implication,

- Defuzzification using the "centroid" method.
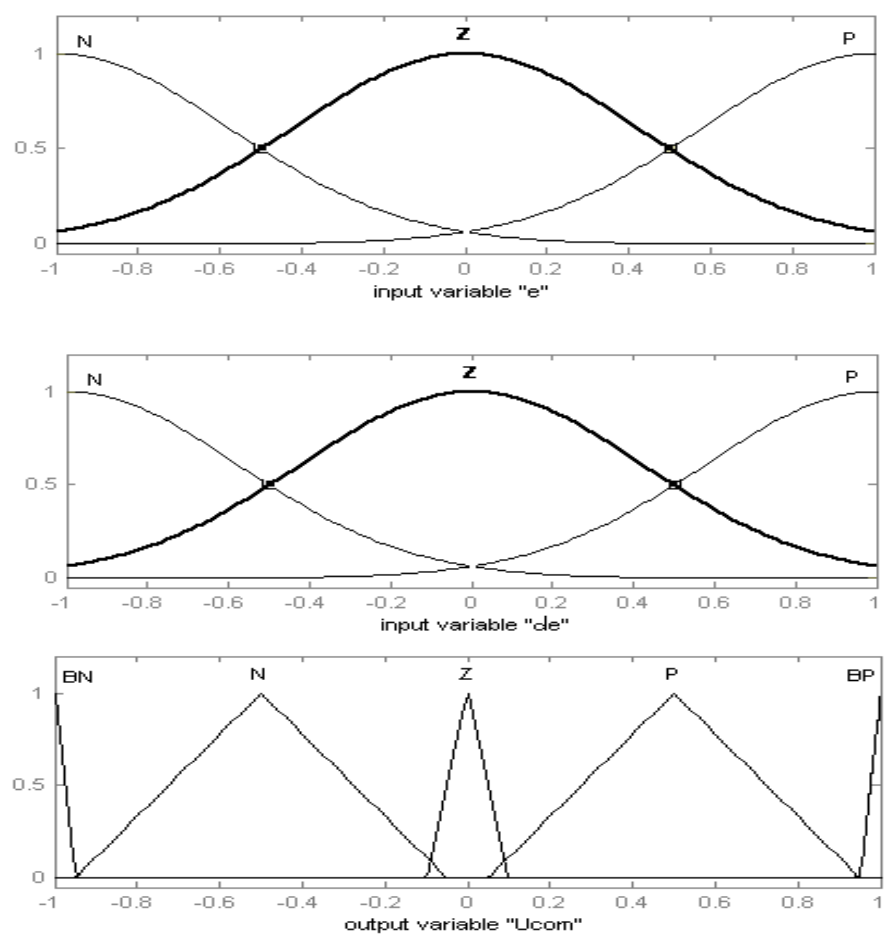

Figure 4. Membership function for the inputs and output variables 
The fuzzy rules are given by:

- If error is Negative and error rate is Negative, Then output is Big Negative,

- If error is Zero and error rate is Negative, Then output is Positive,

- If error is Positive and error rate is Negative, Then output is Big Positive,

- If error is Negative and error rate is Zero, Then output in Big Negative,

- If error is Zero and error rate is Zero, Then output is Zero,

- If error is Positive and error rate is Zero, Then output is Big Positive,

- If error is Negative and error rate is Positive, Then output is Big Negative,

- If error is Zero and error rate is Positive, Then output is Negative,

- If error is Positive and error rate is Positive, Then output is Big Positive.

Errors for each phase are discredited by the zero order hold blocks. The error rate is derivative of the error and it is obtained by the use of unit delay block. The saturation block imposes upper and lower bounds on a signal. When the input signal is within the range specified by the lower limit and upper limit parameters, the input signal passes through unchanged. When the input signal is outside these bounds, he signal is clipped to the upper or lower bound. The output of the saturation blocks are inputs to fuzzy logic controllers. The outputs of these fuzzy logic controllers are used in generation of pulses switching signals of the three-level inverter. The switching signals are generated by means of comparing a two carrier signals with the output of the fuzzy logic controllers.

The simulink model of the generated switching signals is given by Figure 5 .

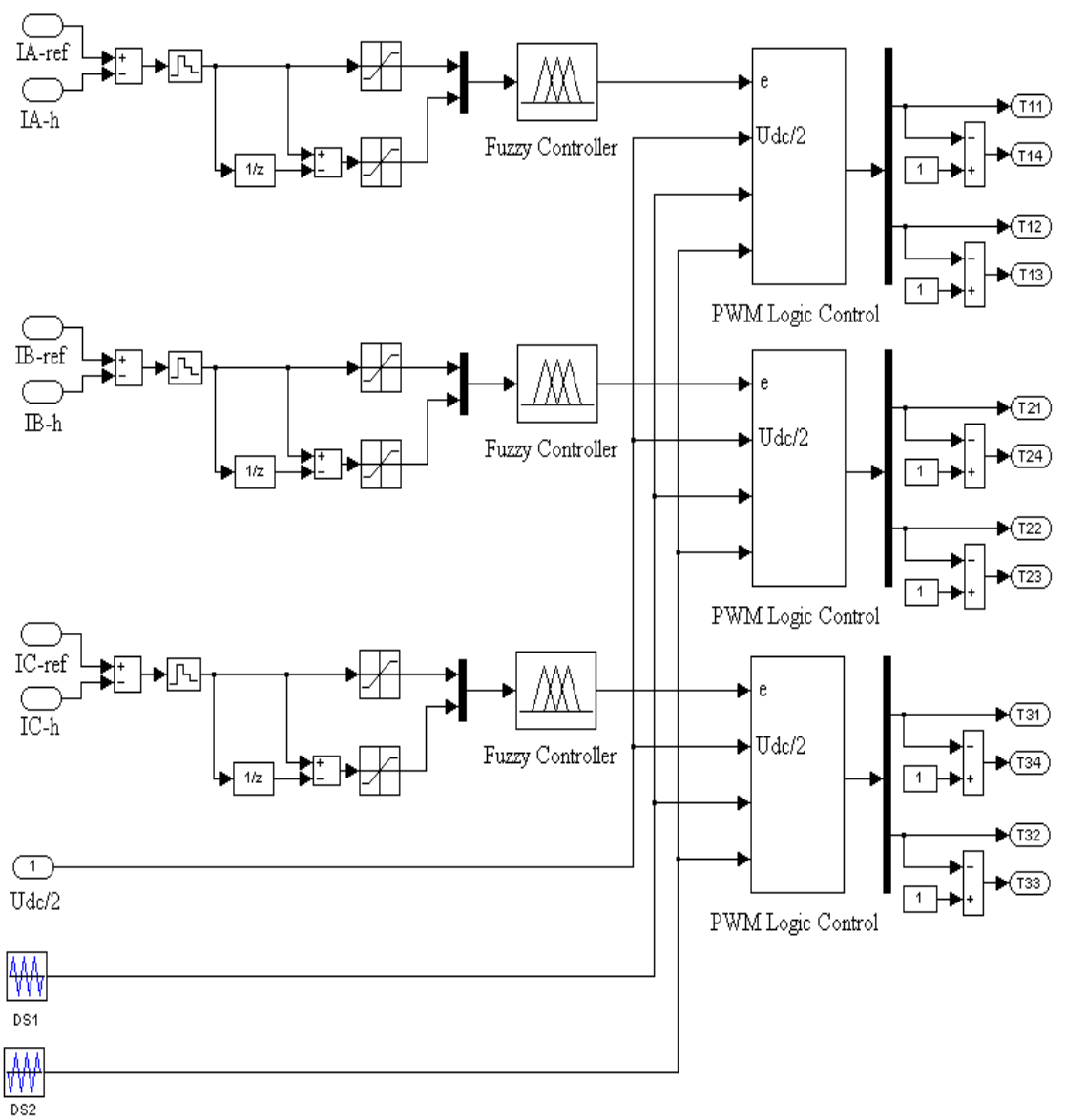

Figure 5. Switching signals generation for the three-level inverter 
The fuzzy logic controller for three-level (NPC) inverter proposed to replace conventional hysteresis controller is shown in Figure 6. The difference between the injected current and the reference current determines the reference voltage (e), and change of error (de), these inputs are injected in fuzzy controller, the fuzzy output is compared with two carrying triangular identical waves shifted one from other by a half period of chopping and generate switching pulses. The control of inverter is summarized in the two following stages:

Determination of the intermediate signals Vi1 and Vi2:

- If error Ec $\geq$ carrying 1 Then Vil $=1$

- If error Ec $<$ carrying 1 Then Vil $=0$

- If error $\mathrm{Ec} \geq$ carrying 2 Then $\mathrm{Vi} 2=0$

- If error Ec $<$ carrying 2 Then $\mathrm{Vi} 2=-1$

Where Vil and Vi2 are intermediate voltage, Ec is the difference between injected and reference currents.

Determination of control signals of the switches Tij and Vi2 $(\mathrm{i}=1,2,3 ; \mathrm{j}=1,2,3,4)$ :

- If $(\mathrm{Vi} 1+\mathrm{Vi} 2)=1$ Then Ti1 $=1, \mathrm{Ti} 2=1, \mathrm{Ti} 3=0, \mathrm{Ti} 4=0$,

- If $(\mathrm{Vi1}+\mathrm{Vi} 2)=0$ Then Ti1 $=0, \mathrm{Ti} 2=1, \mathrm{Ti} 3=1, \mathrm{Ti} 4=0$,

- If $(\mathrm{Vi1}+\mathrm{Vi} 2)=-1$ Then Ti1 $=0, \mathrm{Ti} 2=0, \mathrm{Ti} 3=1, \mathrm{Ti} 4=1$.

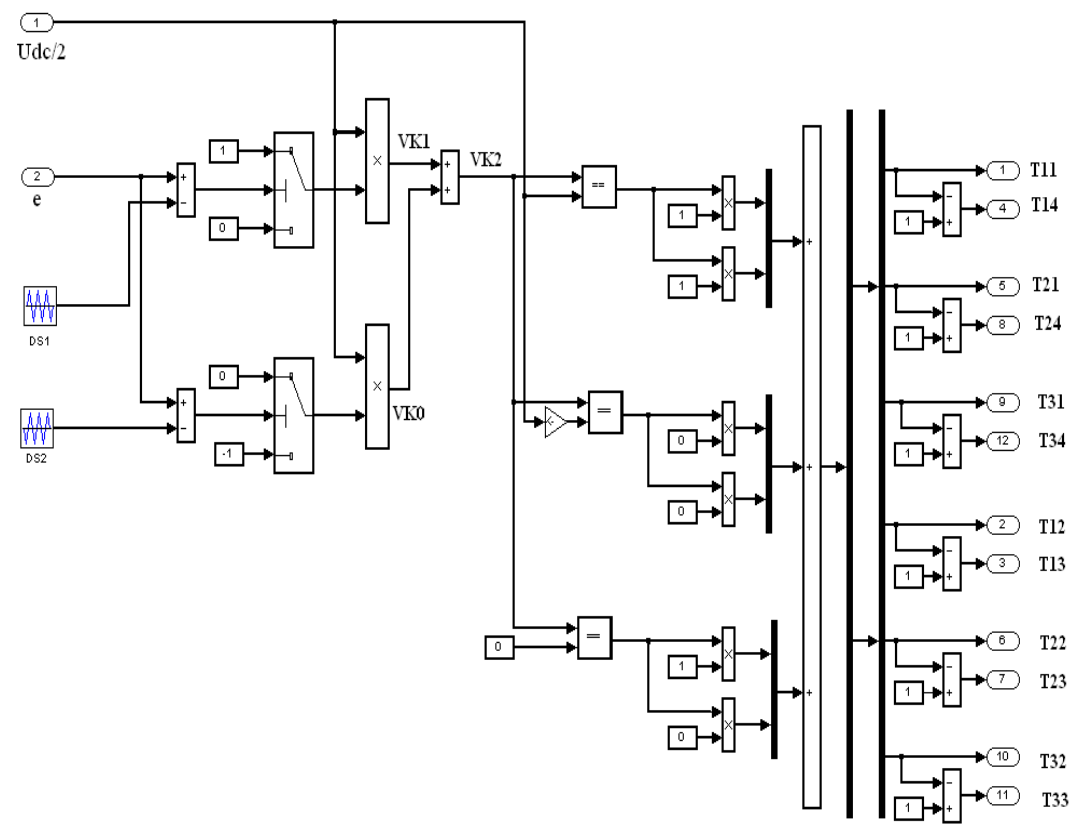

Figure 6. Three-level (NPC) inverter PWM logic control

\section{Simulation results and discussion}

Figure 7 shows the Matlab-Simulink simulation block diagram of the proposed fuzzy current controller for the three-phase shunt active filter under non-ideal voltage conditions. The parameters of the proposed shunt active filter are: Vs $=220 \mathrm{~V}$, Frequency $\mathrm{Fs}=50 \mathrm{~Hz}$, Resistor $\mathrm{Rs}=0.1 \mathrm{~m} \Omega$, Inductance Ls $=0.0002 \mathrm{mH}$, Resistor Rch $=48.6 \Omega$, Inductance $\mathrm{Lch}=40 \mathrm{mH}$, Resistor $\mathrm{Rc}=0.27 \mathrm{~m} \Omega$, Inductance $\mathrm{Lc}=0.8 \mathrm{mH}, \mathrm{Lf}=3 \mathrm{mH}, \mathrm{C} 1=\mathrm{C} 2=300 \mathrm{uF}, \mathrm{Vs}=220 \mathrm{~V} / 50 \mathrm{~Hz}$, Udcref $=800 \mathrm{~V}$. 


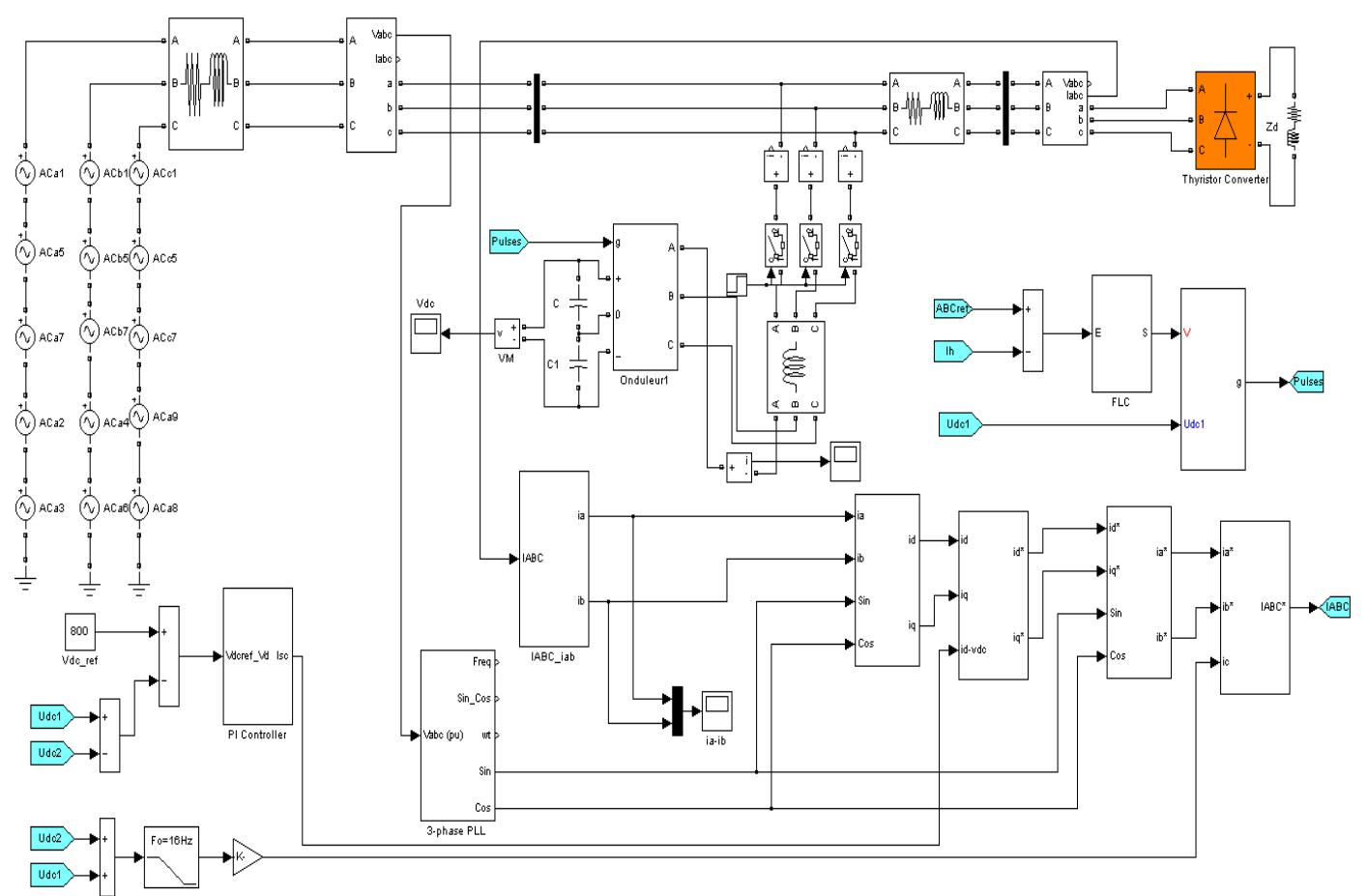

Figure 7. Three-level (NPC) shunt active power filter based on fuzzy controller

The purpose of the simulation is to show the effectiveness of the shunt active filter using a fuzzy current controller to reducing the harmonic currents produced on the load side under non-ideal voltages conditions.

\section{A. Ideal main voltage case}

The three-phase voltages source are balanced and do not contain harmonic components, Figure 8(a), Figure 8(b) and Figure8(c) shows the simulated results of supply voltage, source current before and after compensation using proposed shunt APF system.

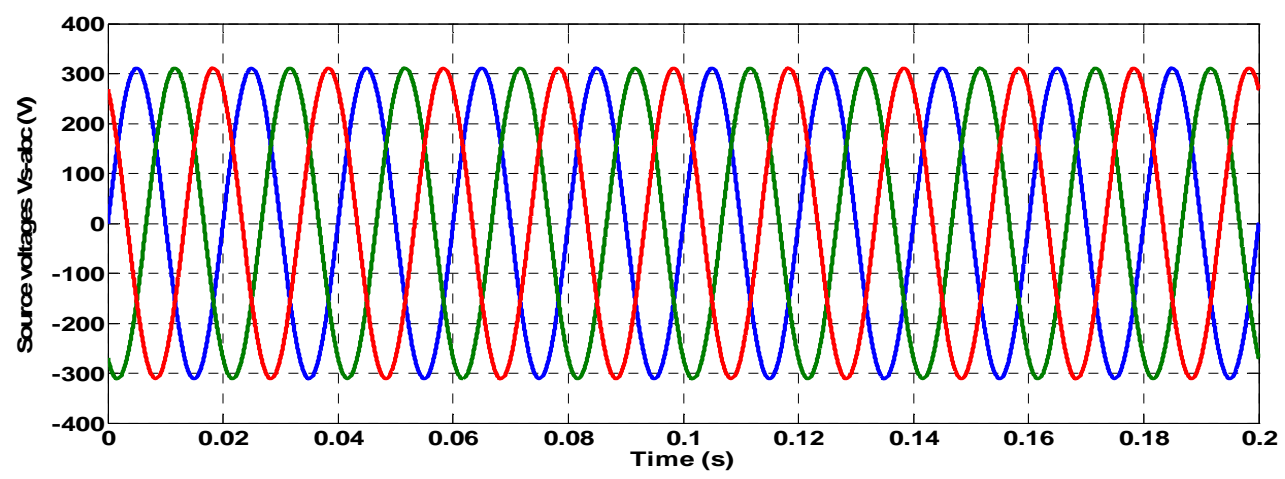

(a)Balanced supply voltage Vs-abc (V) 


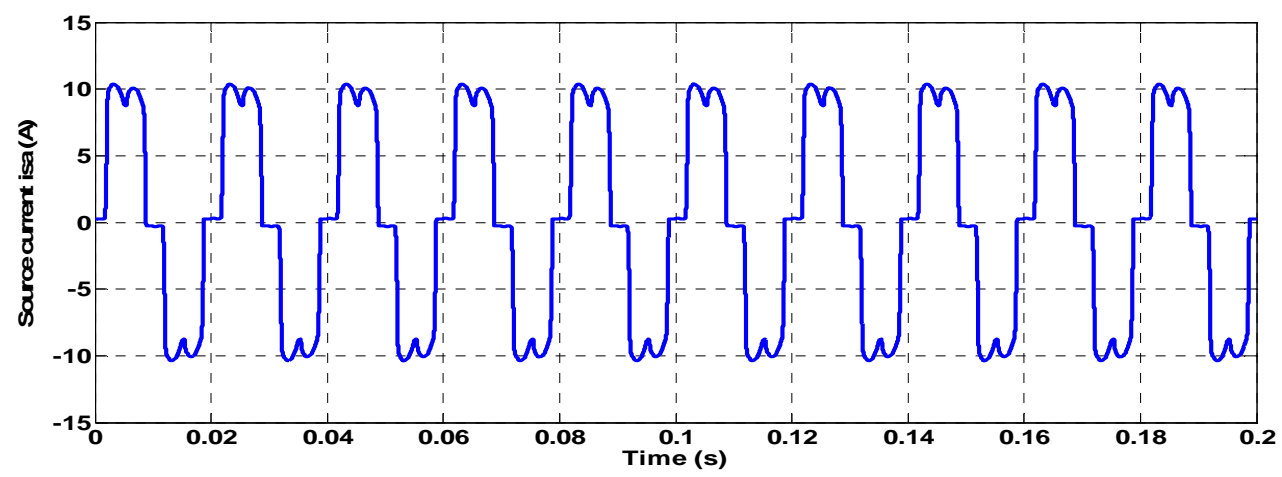

(b) Source current isa(A) before compensation

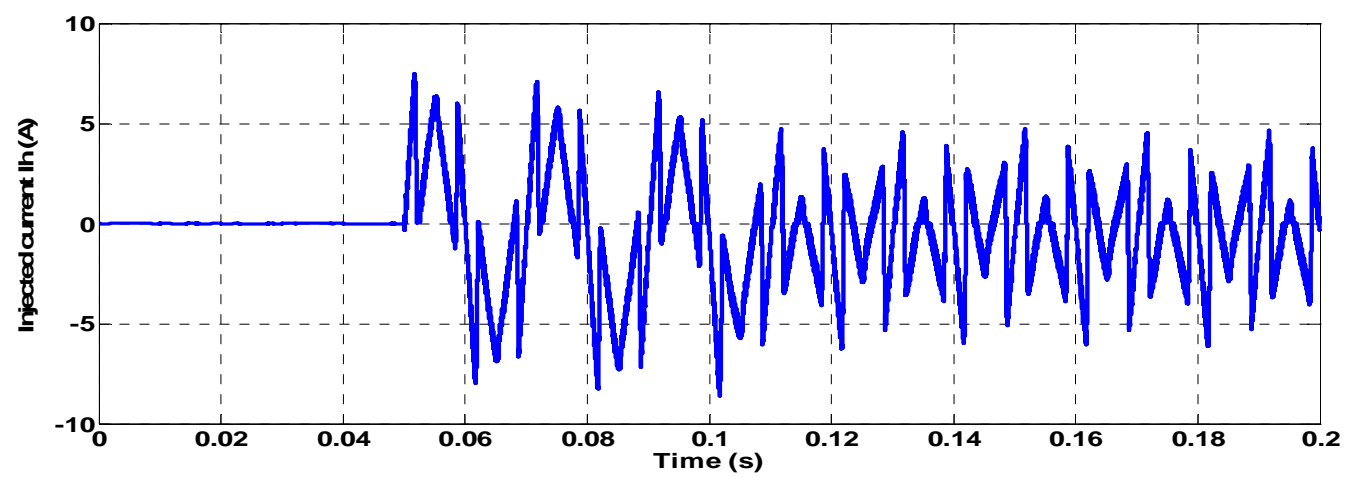

(c) Figure 9. Injected current iha(A)

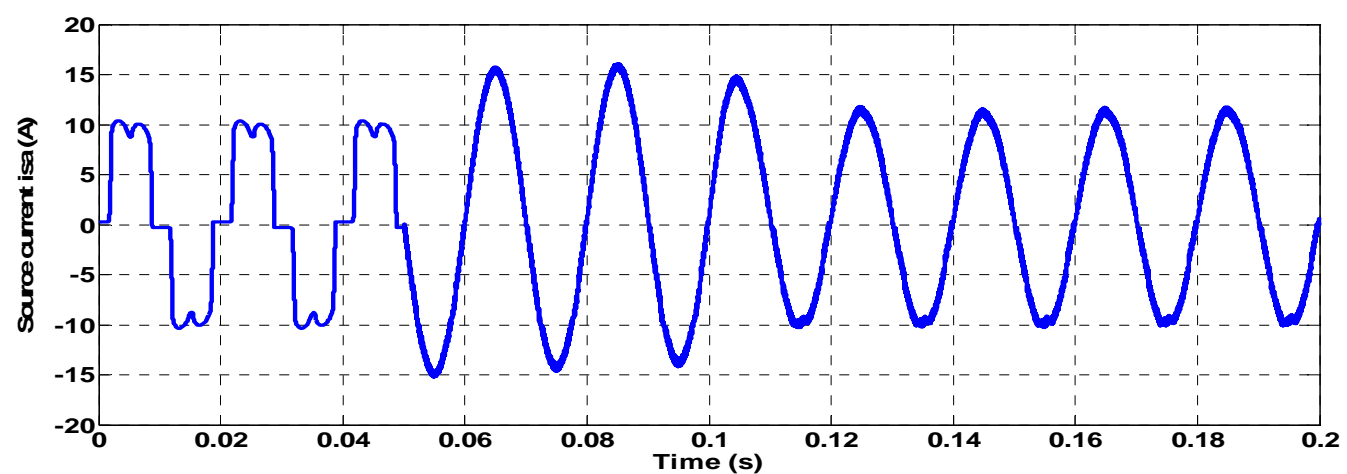

(d) Source current isa(A) after compensation

Figure 8. Source voltage $\mathrm{Vsa}(\mathrm{V})$, injected current iha(A) and source current isa(A) before and after compensation

Before the shunt APF operation between $\mathrm{t} 1=0 \mathrm{~s}$ and $\mathrm{t} 2=0.05 \mathrm{~s}$, the source current is highly distorted and rich on harmonics. It is not in phase with the source voltage, the power factor is poor with high consummation of reactive power. The shunt APF starts the compensation process instantly ( $\mathrm{t} 2=0.05 \mathrm{~s}$ ) when it is connected to the non-linear load. The source current after compensation is practically sinusoidal and in phase with the corresponding source voltage shown by Figure (9). 


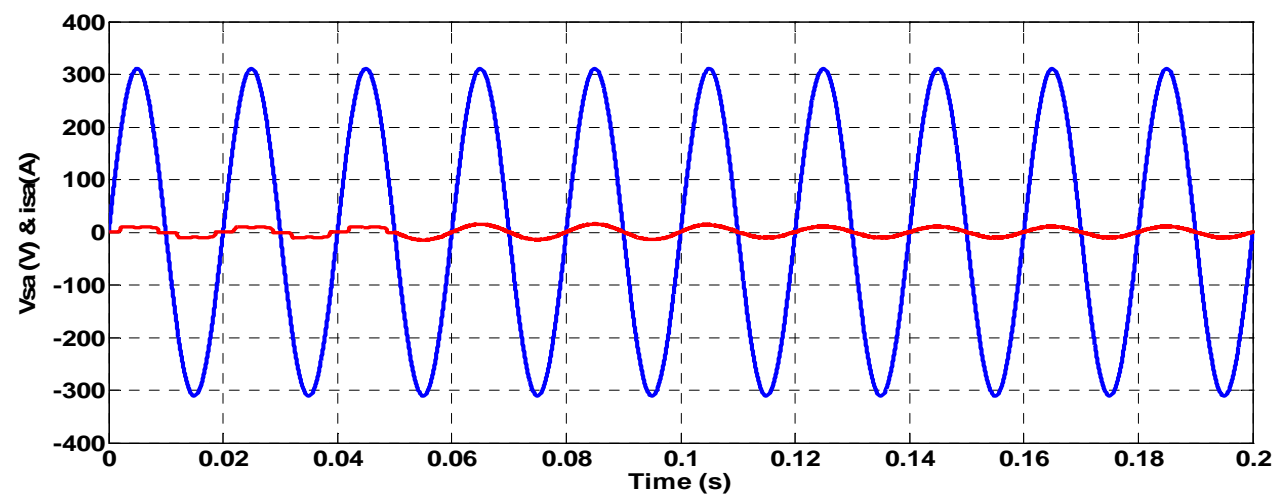

Figure 9. Source current isa(A) and source voltage $\mathrm{Vsa}(\mathrm{V})$ before and after compensation

Figure 10, present the output DC voltages Udc, and Udc1, Udc2, it is shown that the two capacitor voltages are balanced and fellow the similar trace, with small voltage ripples. In this case, the THDi is reduced from $28.16 \%$ to $1.84 \%$ after compensation.

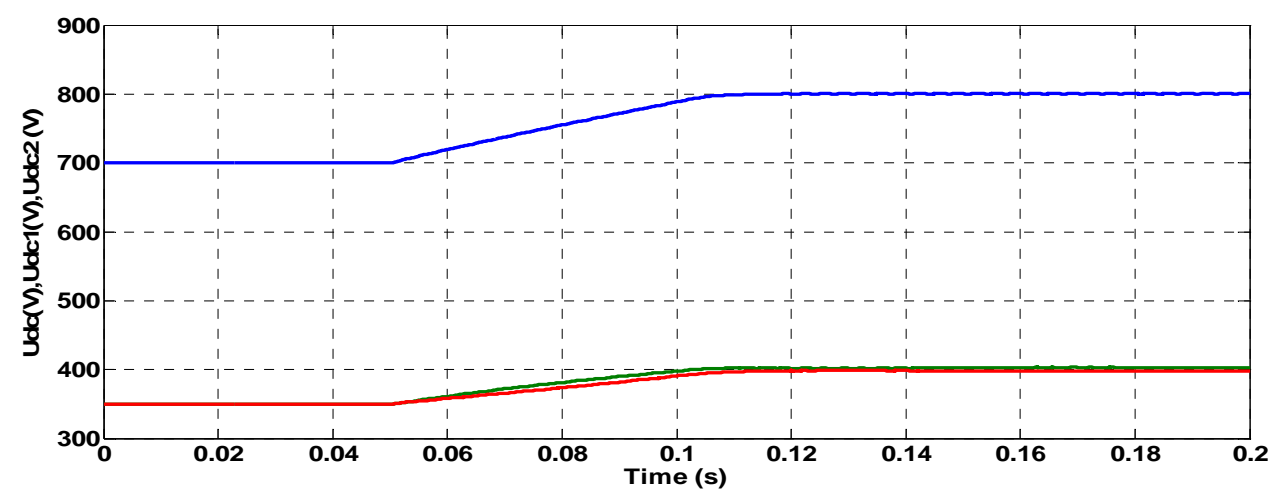

Figure 10. DC output voltages Udc, Udc1 and Udc2

\section{B. Unbalanced mains voltage}

The three-phase voltages sources are unbalanced, but do not contain harmonic components, their expressions are given in (9):

$$
\begin{aligned}
& v_{s a}=311 \sin (\omega t)+31 \sin (\omega t) \\
& v_{s b}=311 \sin \left(\omega t-\frac{2 \pi}{3}\right)+31 \sin \left(\omega t+\frac{2 \pi}{3}\right) \\
& v_{s c}=311 \sin \left(\omega t+\frac{2 \pi}{3}\right)+31 \sin \left(\omega t-\frac{2 \pi}{3}\right)
\end{aligned}
$$

Figure 11 (a), Figure 11 (b) and Figure 11(c) shows respectively the unbalanced voltage source, source current before and after compensation. The current and voltage source is given by Figure 12; finally the dc voltages Udc, Udc1 and Udc2 are shown by Figure 13. 


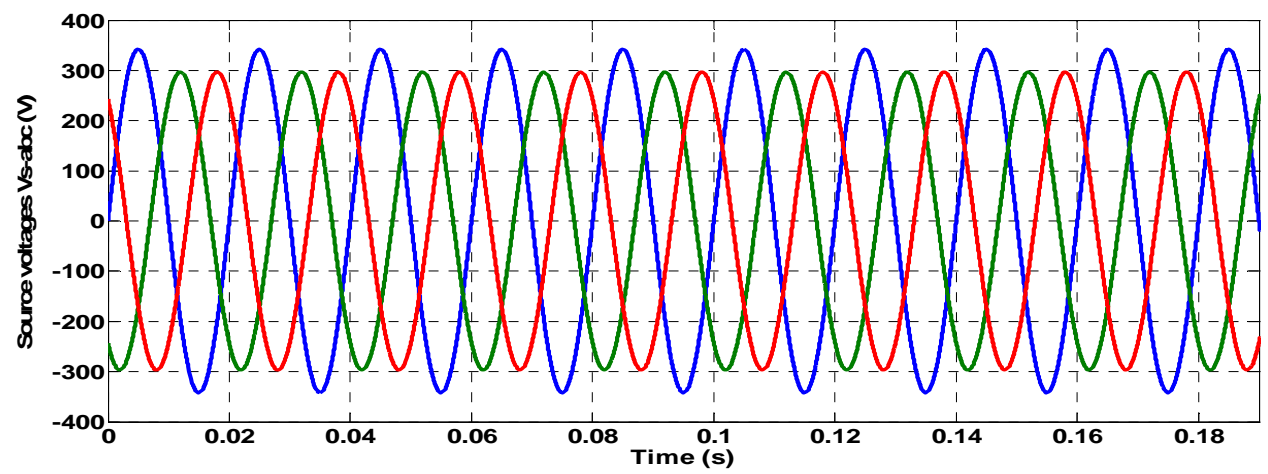

(a) Unbalanced supply voltage Vs-abc (V)

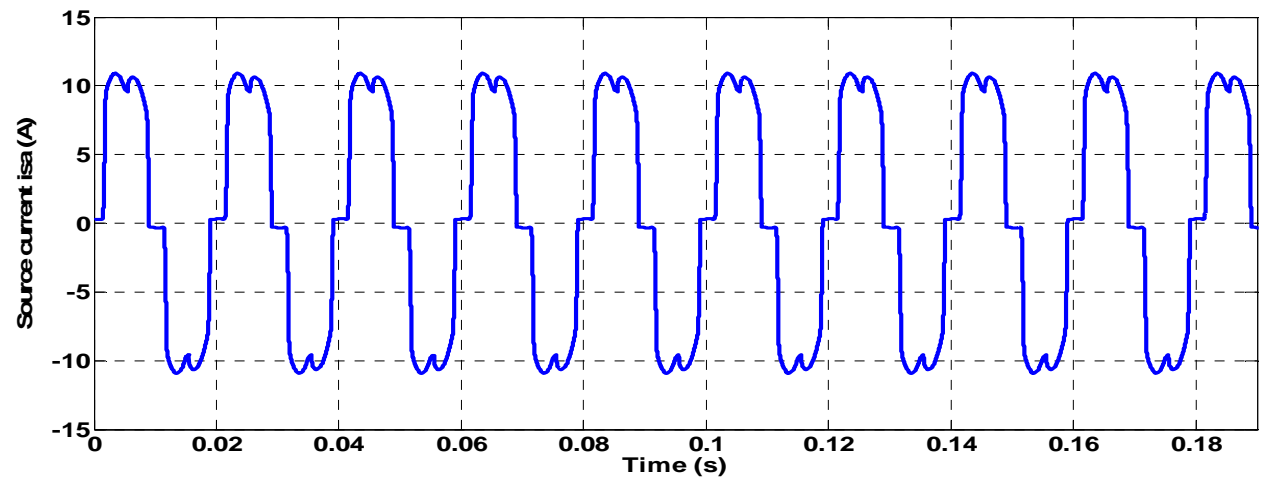

(b) Source current isa(A) before compensation

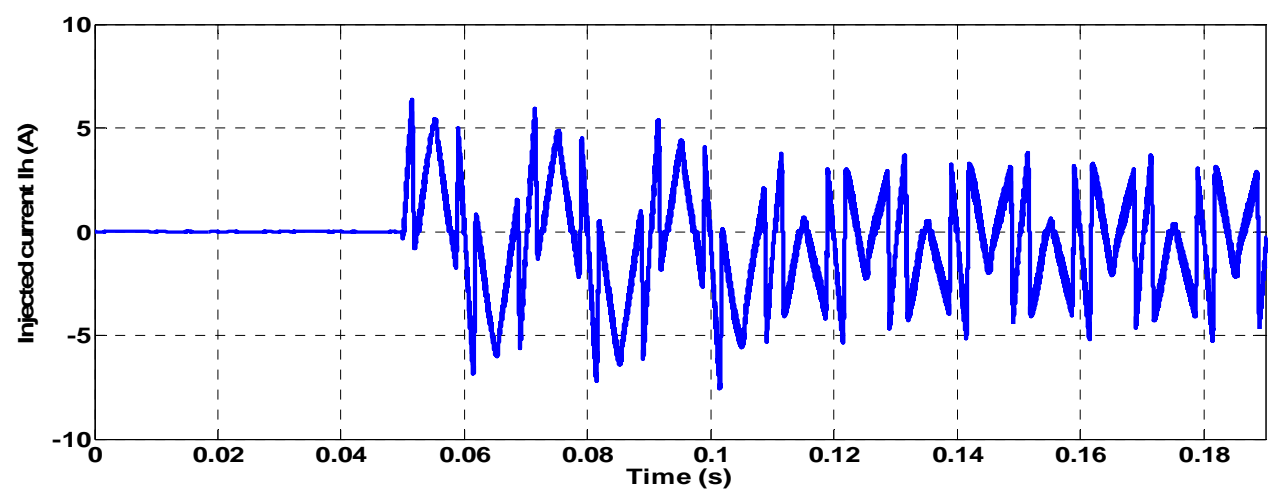

(c) Injected current iha(A) 


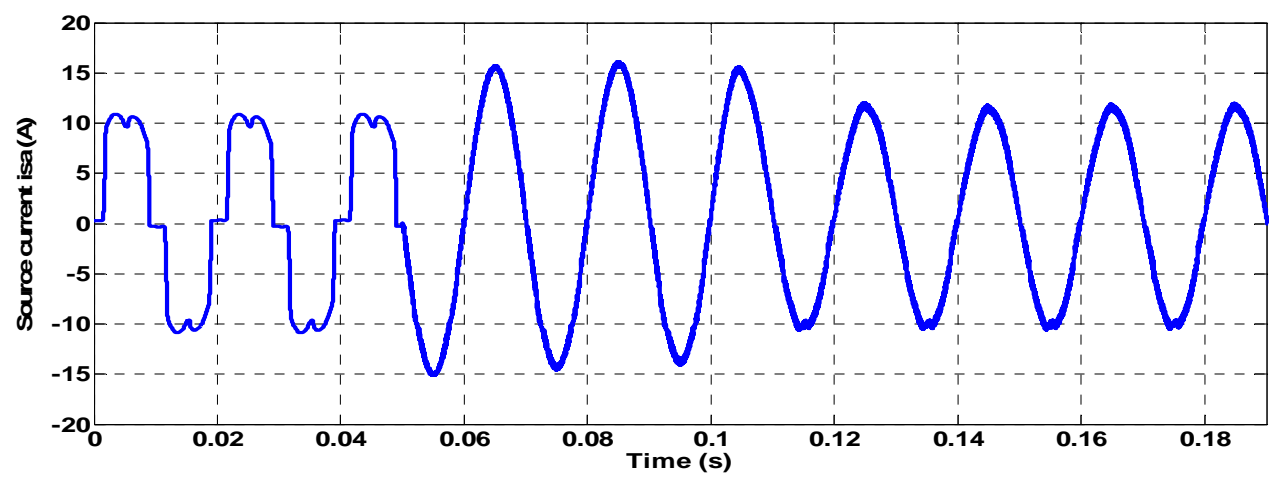

(d) Source current isa(A) before and after compensation

Figure 11. Source voltage $\mathrm{Vsa}(\mathrm{V})$, injected current iha(A) and source current isa(A) before and after compensation

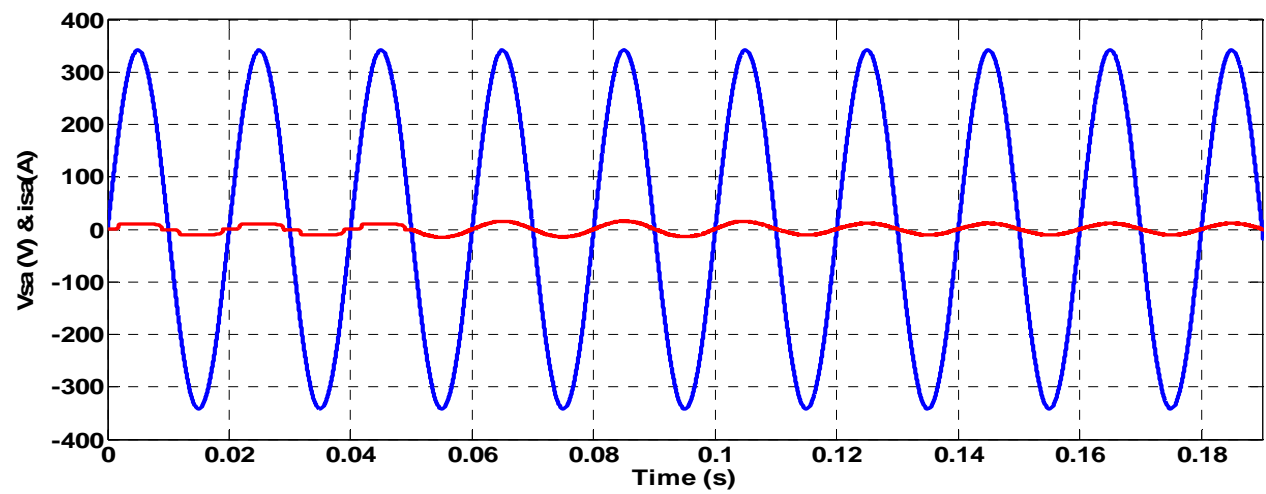

Figure 12. Source current isa(A) and source voltage $\mathrm{Vsa}(\mathrm{V})$ before and after compensation

Figure 13 show DC voltage outputs, the two capacitor voltages are also balanced and follow the similar trace but the voltage ripples on the capacitors now is more than balanced source voltage cases. The THDi is reduced from $28.16 \%$ to $2.12 \%$ after compensation.

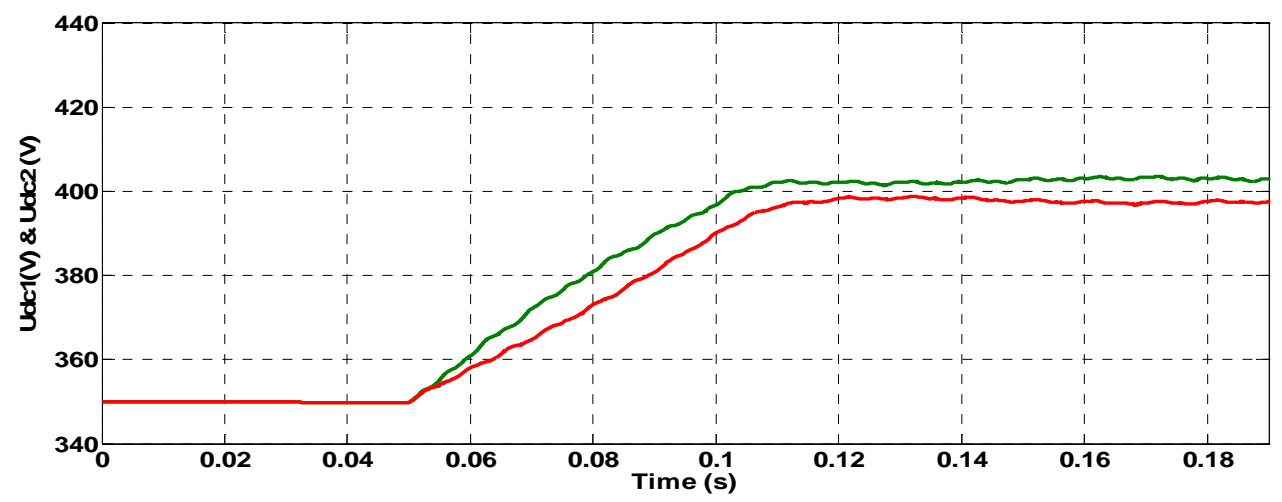

Figure 13. DC output voltages Udc, Udc1, Udc2 


\section{Balanced-distorted voltages source}

When the three-phase voltages are balanced-distorted, mains voltages contain harmonic voltage components except fundamental component. The expression of the balanced-distorted voltages source used in this work contains the 5 th harmonic component and also has the $3^{\text {rd }}, 7^{\text {th }}$, $11^{\text {th }}$ harmonic component. For this case, the balanced distorted tree-phase mains voltages are expressed as below:

$$
\begin{aligned}
& v_{s a}=311 \sin (\omega t)+3.7 \sin (3 \omega t)+18.6 \sin \left(5 \omega t+\frac{4 \pi}{3}\right) \\
& +4.5 \sin (7 \omega t)+3.1 \sin \left(11 \omega t+\frac{4 \pi}{3}\right) \\
& v_{s b}=311 \sin \left(\omega t+\frac{4 \pi}{3}\right)+3.7 \sin (3 \omega t)+18.6 \sin (5 \omega t) \\
& +4.5 \sin \left(7 \omega t+\frac{4 \pi}{3}\right)+3.1 \sin (11 \omega t) \\
& v_{s c}=311 \sin \left(\omega t+\frac{2 \pi}{3}\right)+3.7 \sin (3 \omega t)+18.6 \sin \left(5 \omega t+\frac{2 \pi}{3}\right) \\
& +4.5 \sin \left(7 \omega t+\frac{2 \pi}{3}\right)+3.1 \sin \left(11 \omega t+\frac{2 \pi}{3}\right)
\end{aligned}
$$

Figure 15(a), Figure 15(b) and Figure 15(c) shows the unbalanced voltage source, line current (before and after compensation). Figure 16, shows the current and voltage source, and finally the dc voltage is presented in Figure 17.

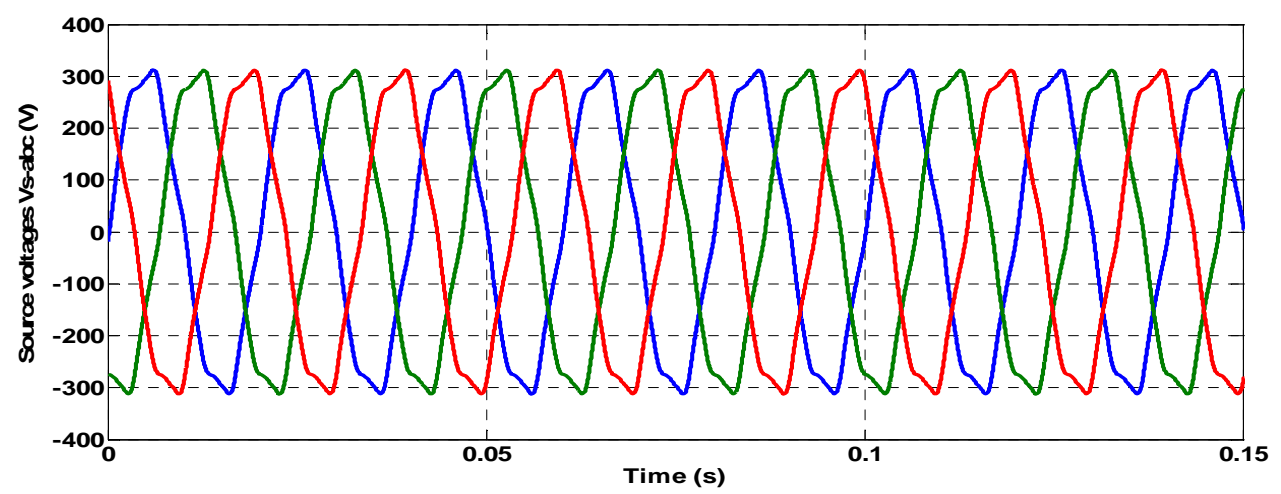

(a) Balanced-distorted supply voltage Vs-abc (V)

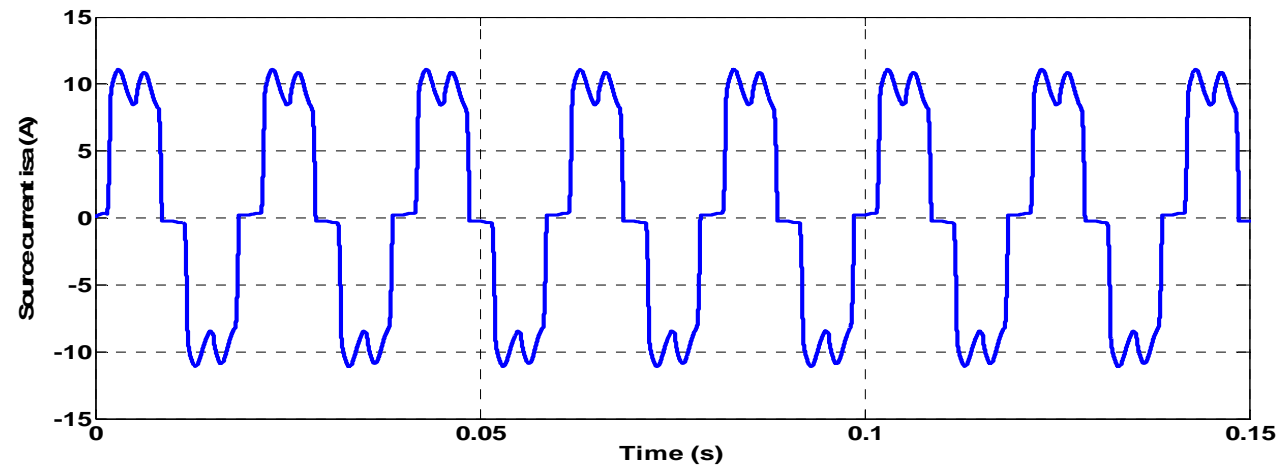

(b) Source current isa (A) before compensation 


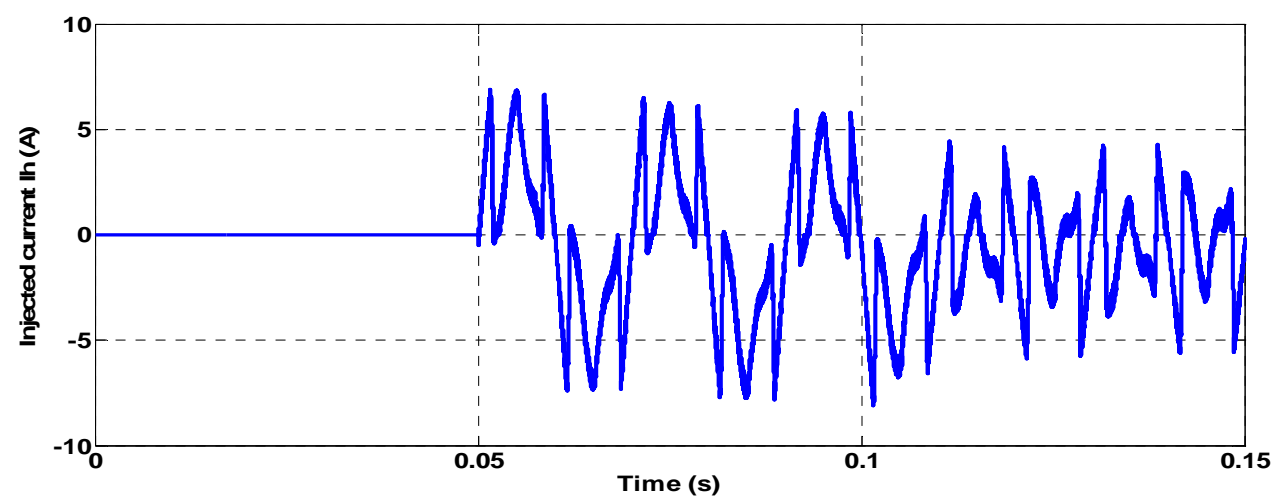

(c) Injected current iha(A)

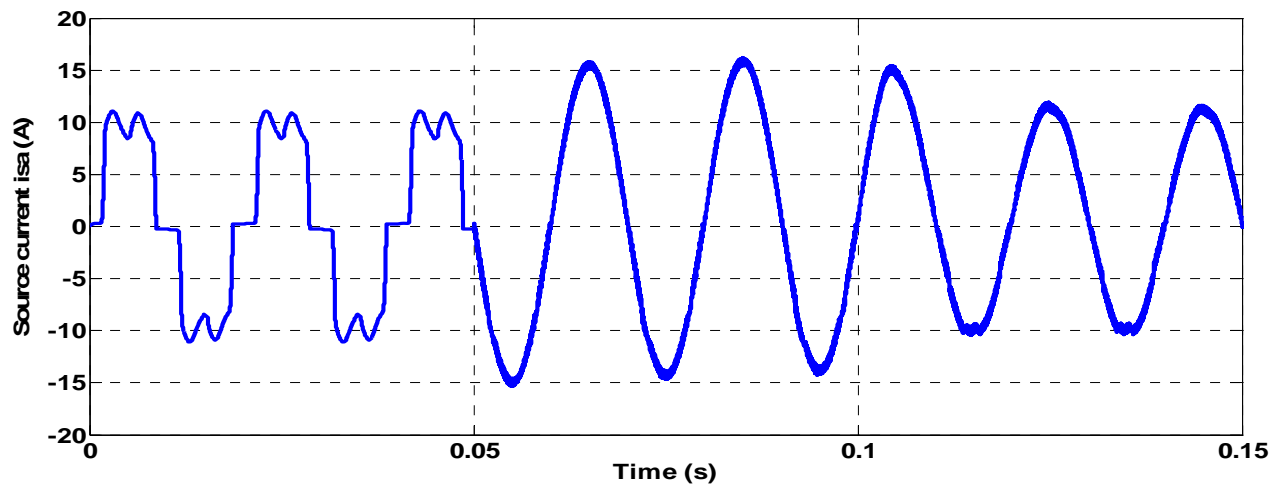

(d) Source current isa (A) before and after compensation

Figure 15. Source voltage Vsa(V), injected current iha(A) and source current isa(A) before and after compensation

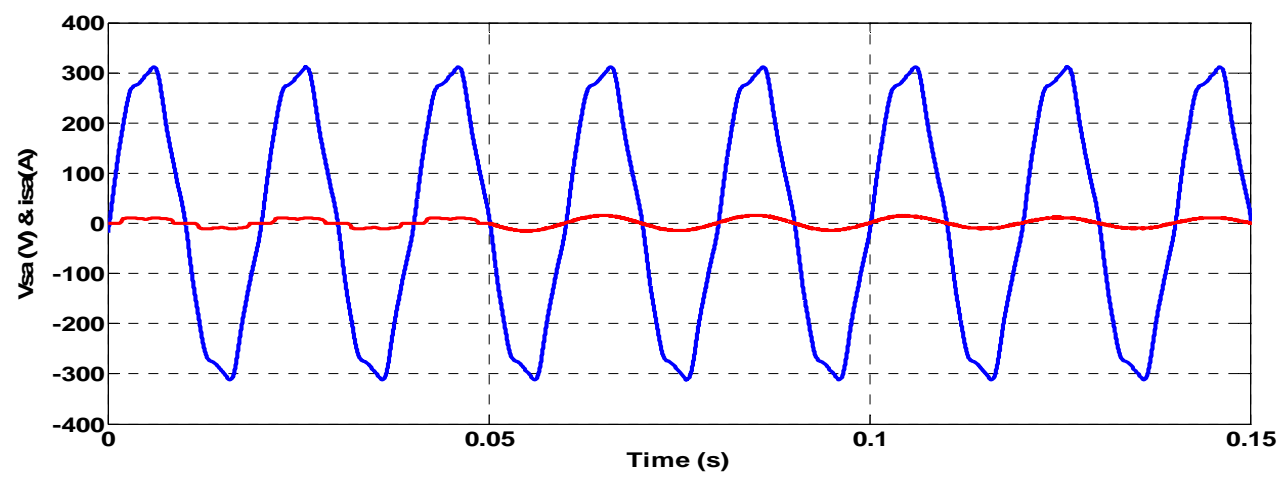

Figure 16. Source current isa (A) and source voltage $\mathrm{Vsa}(\mathrm{V})$ before and after compensation

Figure 17 show DC voltage outputs, the two capacitor voltages are also balanced and follow the similar trace but the voltage ripples on the capacitors now is small than unbalanced source voltage cases. The THDi is reduced from $28.16 \%$ to $2.09 \%$ after compensation. 


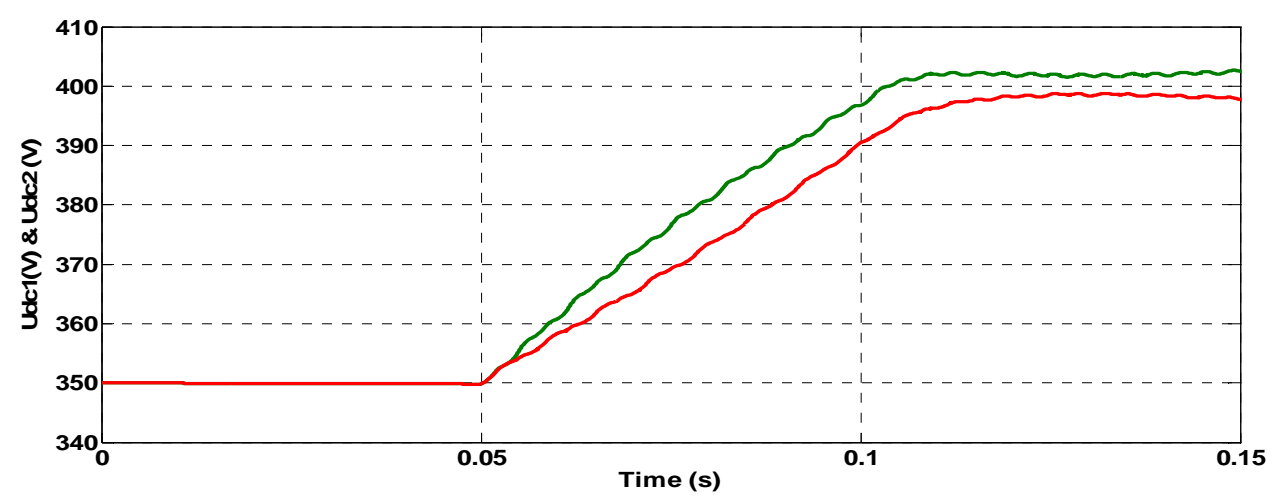

Figure 17. DC output voltages Udc, Udc1 and Udc2

By visualizing different figures of the current source after compensation in all cases of voltage source, we can conclude the success in simulating of the harmonic currents compensation using the proposed fuzzy logic current controller. The performance of the threelevel shunt active filter based on FLC controller in terms of eliminating harmonics are very acceptable. The THDi values obtained in the three studied cases $(1.84 \%, 2.12 \%$ and $2.09 \%)$ respect the IEEE standards Norms (THDi $\leq 5 \%$ ). The PI regulator used ensures that the DC voltage across the capacitor is constant and equal to Udc-ref $=800 \mathrm{~V}$ with a fast dynamic response. The proposed proportional controller added to DC voltage control loop improves the performances of active power filter Figures (10), (13) and (17) shows the dc voltage output; the voltage ripple in unbalanced voltage case is more than distorted voltage case. The compensation of the neutral-point voltage based on proportional controller is used to improve the output multilevel voltage converter and to avoid an unbalanced $\mathrm{AC}$ voltage waveform on the AC terminals.

\section{Conclusion}

In this paper, a three-phase three-level shunt active filter based on neutral-point diode clamped inverter based on PWM fuzzy logic current controller has been adopted to compensate harmonic currents under non ideal voltage conditions. The proposed PWM-FLC is designed to improve compensation capability of APF by adjusting the current error using a fuzzy rule to generate the PWM switching signals. To regulate dc bus voltage and compensate the power loss of the active filter a simple PI voltage controller is used in outer loop. To improve the output three-level voltage inverter and to avoid an unbalanced AC voltage waveform on the AC terminals a neutral-point potential voltage compensator based on proportional controller is added to DC voltage in inner control loop. The simulation results prove the effectiveness of the designed shunt active filter based on PWM fuzzy logic controller. The source current becomes closely sinusoidal and in phase with voltage source and the THD is reduced after compensation to $1.84 \%, 2.12 \%$ and $2.09 \%$ for the three cases studied in conformity with the standard IEEE recommendations (THD $<=5 \%$ ).

\section{References}

[1] O. Vodyakho, T. Kim, S. kwak, "Comparison of the space vector current controls for shunt active power filters", IEEE, pp. 612-617, 2008.

[2] Udom. Khruathep, Suittichai Premrudeepreechacharn, Yuttana Kumsuwan, "Implementation of shunt active power filter using source voltage and source current detection", IEEE, pp 2364-2351, 2008.

[3] A. Zouidi; F. Fnaiech, K. Al-Haddad, "Voltage source inverter based three-phase shunt active power filter :Topology, Modeling and control strategies", IEEE, ISIE, pp 785-790, 2006. 
[4] S. Bhattacharya, T.M Frank, D.M Divan, B.Banerjee, "Active filter system implementation", IEEE, Trans. On Industry Applications, Vol.4, Issue 5, pp. 47-63, 1998.

[5] M. Routimo, M. Salo, H.Tuusa, "Comparaison of voltage source and current source shunt active power filter”, IEEE, Trans. On Power Electronics, Vol.22, Issue 2, pp 636-643, 2007.

[6] O. Vodyakho, D. Hackstein, A. Steimel, T. Kim, "Novel direct current-space vector control for shunt active power filters based on three-level inverters", IEEE, pp. 1868$1873,2008$.

[7] G. Liu, S. Su, P. Peng, "Intelligent Control and Application of All-function Active Power Filter", IEEE, International Conference on Intelligent Computation Technology and Automation, pp. 1078-1081, 2008.

[8] Kerrouche Soumia, Krim Fateh, "Three-phase active power filter based on fuzzy logic controller", International Journal of Sciences and techniques of automatic Control \& Computer engineering, Volume 3, $\mathrm{N}^{\circ} 1$, pp 942-955, 2009.

[9] M.Sarra, K.Djazia, A.Chaoui, F.Krim, "Three-phase active power filter with integratorproportional control", 3rd International conference on electrical engineering, pp 506$511,2009$.

[10] B.Sing, K.Haddad, A.Chandra, "A new control approach to three-phase active filter for harmonics and reactive power compensation", IEEE,Trans. Power Syst.13(1), pp 133$138,1998$.

[11] S. Chennai, M-T. Benchouia, “ Three-phase Three-level (NPC) Shunt Active Power Filter Performances based on PWM and ANN's Controllers for Harmonic Current Compensation", International Journal on Electrical Engineering and Informatics, IJEEI, March, Vol.6, No.1, pp.213-234, 2014.

[12] Hugh Rudnick, Juan Dixon and Luis Moran, "Delivering clean and pure power," IEEE, power \& Energy magazine, pp. 32-40, 2003.

[13] S. Chennai and M-T. Benchouia, "Simplified Control Scheme of Unified Power Quality Conditioner based on Three-phase Three-level (NPC) inverter to Mitigate Current Source Harmonics and Compensate All Voltage Disturbances", Journal of Electrical Engineering \& Technology, JEET (KIEE), Vol.8, No.3, pp.544-558, May 2013.

[14] E.E. El-Kholy, A. El-Hefnawy, H.M Mahrous, "Three-phase active power based on current controlled voltage source inverter", Elsevier, Electric power and Energy Systems 28, pp. 537-547, 2006.

[15] S.GH Seifossadat, R.Kianinezhad, A.Ghasemi, M.Monadi, "Quality improvement of shunt active power filter, using optimized tuned harmonic passive filters", International Symposium on Power Electronics, Electrical Drives, Automation and motion, SPEEDAM 2008, pp. 1388-1393, 2008.

[16] Yingjie He, Jinjun Liu, Jian Tang, Zhaoan Wang and Yunping Zou, "Research on control system of DC voltage for active power filters with three-level NPC inverter", IEEE, pp. 1173-1178, 2008.

[17] H.B Zhang, S.J.Finney, A.M.Massoud, J.E.Fletcher, B.W.Williams, "Operation of a three-level NPC active power filter with unbalanced and non-linear loads", IEEE, pp. 2226.

[18] T.N.Reddy, M.V.Subramanyam, "Fuzzy logic controlled shunt active power filter for mitigation of harmonics with different membership functions", International Conference on Advances in Computing, Control on Advances in Computing, Control and Telecommunication Technologies, pp 616-620, 2009.

[19] S. Chennai, M-T. Benchouia and A. Goléa, "Harmonic currents compensation based on three-phase three-level shunt active filter using fuzzy logic current controller", Journal of Electrical Engineering \& Technology JEET (KIEE), September, Vol.6, No.5, pp.595-604, 2011. 
[20] S. Chennai, M-T. Benchouia, "Intelligent controllers for shunt active filter to compensate current harmonics based on SRF and SCR control strategies", International journal on Electrical Engineering and Informatics, IJEEI, Vol.3, No.3, pp. 372-393, 2011.

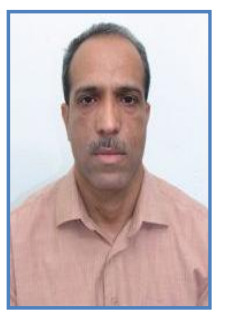

Chennai Salim Was born in Biskra, Algeria, on February 03, 1969. He obtained his engineering degree in Electrotechnics from Biskra University in 1992. He was recruited in 1993 as senior engineer in power electronics in Birine Nuclear Research Center, Algeria. Since 2000, he has been working as researcher in the Electrical Engineering Department. He obtained his M.Sc degree in electrical engineering in 2009 from Media University, Algeria and his Ph.D. degree in Electrical Engineering from Biskra University in 2013, Algeria. His research interests are electrical drives, power electronics, power quality energy improvement, power systems and intelligent control.

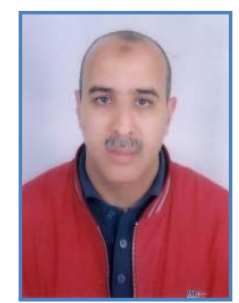

Benchouia Mohamed Toufik Was born in Biskra, Algeria. He received his Engineer degree in Electrotechnics and M.Sc degree in electrical engineering from Biskra University in 1991 and 1998 respectively. He received his Ph.D. in electrical engineering from Biskra University in 2006. Since 2001 he has held a teaching and research position in the Electrical Engineering Department of Biskra University, Algeria. His research interests are in electrical drives, power electronics and power systems. 